\title{
COMPARATIVE STUDY OF ATTEMPTED SUICIDES AND PSYCHIATRIC OUT-PATIENTS
}

\author{
BY \\ JOHN G. BRUHN* \\ From the Medical Research Council Unit, Department of Psychological Medicine, University of Edinburgh
}

The social pathology of attempted suicide in Great Britain has been intensively investigated by Stengel and Cook (1958) and Kessel and Lee (1962). Attempted suicides have also been studied in the context of the general hospital by Woodside (1958), and Harrington and Cross (1959), and in that of general practice by Batchelor (1955).

The purpose of the present investigation was to compare attempted suicides with other patients referred for psychiatric treatment (controls) and discover whether attempted suicides have a greater degree of social disorganization than is usually found among other psychiatric patients. The factors of social disorganization investigated were the broken home, unstabilizing factor in the household, unemployment, change(s) of address, and marital disharmony.

\section{Method}

143 persons were admitted to Ward 3 of the Royal Infirmary, Edinburgh, from November, 1961, to February, 1962, after "attempted suicide". 91 of them complied with our definition of suicide, namely, any act of self-injury performed with the intent of taking one's life, and those who made only verbal threats and doubtful cases (i.e. in which the intention

* Present Address: University of Oklahoma Medical Center, Oklahoma City 4, Oklahoma, U.S.A. of the act was unclear) were excluded from the survey. + The controls consisted of 91 psychiatric out-patients who had never attempted suicide and who were attending the Psychiatric Out-Patient Clinic of the Royal Infirmary of Edinburgh or Jordanburn Nerve Hospital, during the same time. Each case/control pair was matched by sex, age, and occupation. Diagnosis and previous psychiatric treatment were not controlled factors. The rationale underlying the selection of the controls was the assumption that the attempted suicides were also emotionally disturbed before the attempt.

The cases and controls were interviewed upon admission by the author and information obtained at the interview was checked with information elicited by the psychiatrist. Interview data was also checked with medical record data if such existed at the Royal Infirmary.

\section{FINDINGS}

(1) Age, Sex, and Marital Status.-In Table I the distribution of the attempted suicides by age and

+49 admissions were excluded because the intention of suicide was not explicit or were not detained long enough to be interviewed. Thre patients who refused to co-operate were also excluded.

TABLE I

SEX AND AGE OF ATTEMPTED SUICIDE CASES AND EDINBURGH RESIDENTS

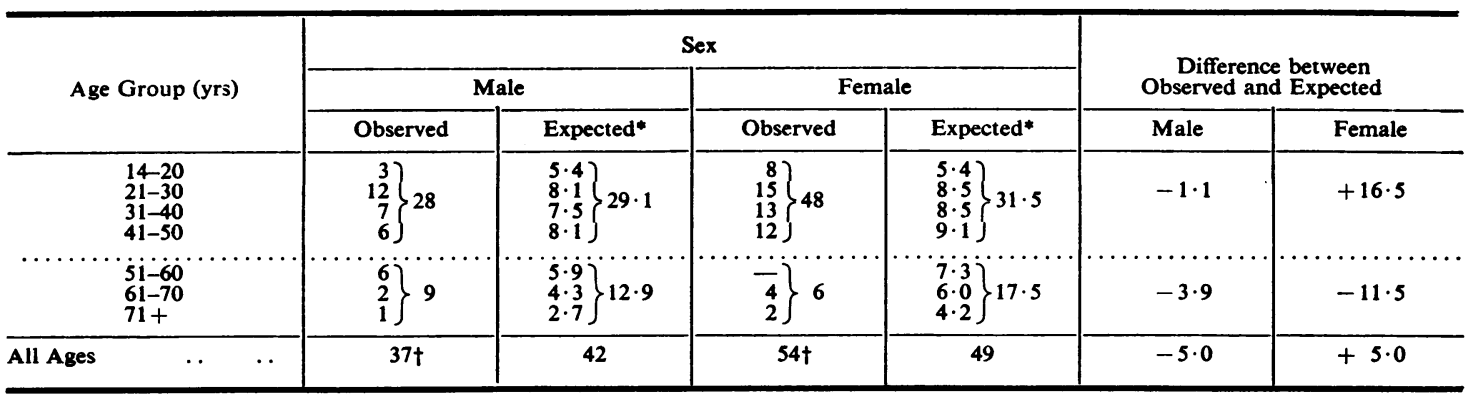

* Based on Edinburgh residents 1951 census.

t Mean age of males 39 yrs. Mean age of females $37 \mathrm{yrs}$. 
sex is compared with that expected on the basis of the population of the city of Edinburgh. Part of the excess of women over men among attempted suicides of all ages, 54 women to 37 men, can be attributed to population differences and the ratios observed : expected being just below unity for men and just above for women. For men the observed and expected numbers are also similar when two age groups, under and over 50 years of age, are considered separately. Among women, however, the two age groups behave very differently. Below 50 attempted suicide was more frequent than expected (48 observed to 31.5 expected) but in older women it was less frequent (only six observed to $17 \cdot 5$ expected).

Table II shows that more controls than cases among both sexes are married and that fewer are separated or divorced. This may be due to a greater degree of stability on the part of the controls, with the view that marriage represents a central adjustment area in life. Among the male controls, fewer are married and more are single, than in the Edinburgh population, but there is an opposite trend among the female controls. A slight excess of the separated or divorced among the controls of both sexes also distinguishes them from the Edinburgh population. These differences between the control sample and the Edinburgh population may reflect sex and marital status differences between the psychiatric out-patient population and the general population.

Table II shows that among the men who attempted suicide there were also fewer married and more single than would be expected from the distribution in the Edinburgh population. There was also a considerable excess of separated or divorced men. For female patients, on the other hand, the proportion of married women was similar to that in the Edinburgh resident population; there was some deficiency of single women but, as in men, an excess of those separated or divorced. The prevalence of attempted suicide among the separated and divorced has also been reported by Piker (1938) and Dahlgren (1945). The proportion of widowed persons among the patients who attempted suicide was similar in both sexes to that in the Edinburgh population.

(2) Factors of Social Disorganization.-These are set out in Table III (opposite).

(i) The Broken Home.-This was defined as the absence or loss of one or both parents, by death or by separation due to marital disharmony, for periods of 6 months or more before the patient was 15 years old (excluding temporary absences during the war).

38 (42 per cent.) of the cases came from a broken home in contrast with 23 (25 per cent.) of the controls. Varying figures on the prevalence of the broken home among attempted suicides have been reported in many studies (Batchelor and Napier, 1953; Palmer, 1941 ; Reitman, 1942; Zilboorg, 1936; Stengel and Cook, 1958). Although the broken home is important, it is only one of a constellation of aetiological factors contributing to attempted suicide. In a recent study regarding broken homes among attempted suicides it was found that the broken home becomes causally significant only when other indications of social disorganization are also found (Bruhn, 1962).

(ii) Unstabilizing Factor in Household.-We were also interested in whether the patient had experienced the absence and/or death of a member of the family in the year before admission. This should not be construed as an assessment of household stability, but rather of whether the patient had encountered an upsetting or stressful event in his household.

TABLE II

MARITAL STATUS OF ATTEMPTED SUICIDE CASES, CONTROLS, AND EDINBURGH RESIDENTS

\begin{tabular}{|c|c|c|c|c|c|c|c|c|}
\hline \multirow{2}{*}{\multicolumn{2}{|c|}{ Marital Status }} & & \multicolumn{3}{|c|}{ Male } & \multicolumn{3}{|c|}{ Female } \\
\hline & & & No. of Cases & No. of Controls & $\begin{array}{c}\text { Edinburgh } \\
\text { Residents } \\
\text { (Expected No.)* }\end{array}$ & No. of Cases & No. of Controls & $\begin{array}{c}\text { Edinburgh } \\
\text { Residents } \\
\text { (Expected No.)* }\end{array}$ \\
\hline $\begin{array}{l}\text { Married } \\
\text { Single } \\
\text { Widowed } \\
\text { Separated }\end{array}$ & $\begin{array}{l}\cdots \\
\cdots \\
\text { or Divorced }\end{array}$ & $\begin{array}{l}\ddot{ } \\
\ddot{*} \\
\dot{ }\end{array}$ & $\begin{array}{r}13 \\
14 \\
2 \\
8\end{array}$ & $\begin{array}{r}18 \\
16 \\
2 \\
1\end{array}$ & $\begin{array}{r}24 \cdot 2 \\
10 \cdot 5 \\
2 \cdot 0 \\
0 \cdot 3\end{array}$ & $\begin{array}{r}26 \\
13 \\
7 \\
8\end{array}$ & $\begin{array}{r}37 \\
12 \\
2 \\
3\end{array}$ & $\begin{array}{r}28 \cdot 9 \\
17 \cdot 1 \\
7 \cdot 4 \\
0.6\end{array}$ \\
\hline Total & $\ldots$ & $\ldots$ & 37 & 37 & $37 \cdot 0$ & 54 & 54 & $54 \cdot 0$ \\
\hline
\end{tabular}

* Based on Edinburgh residents 1951 census. 
TABLE III

FACTORS OF SOCIAL DISORGANIZATION, PRESENTING PROBLEMS AND DIFFERENCES BETWEEN CASES AND CONTROLS

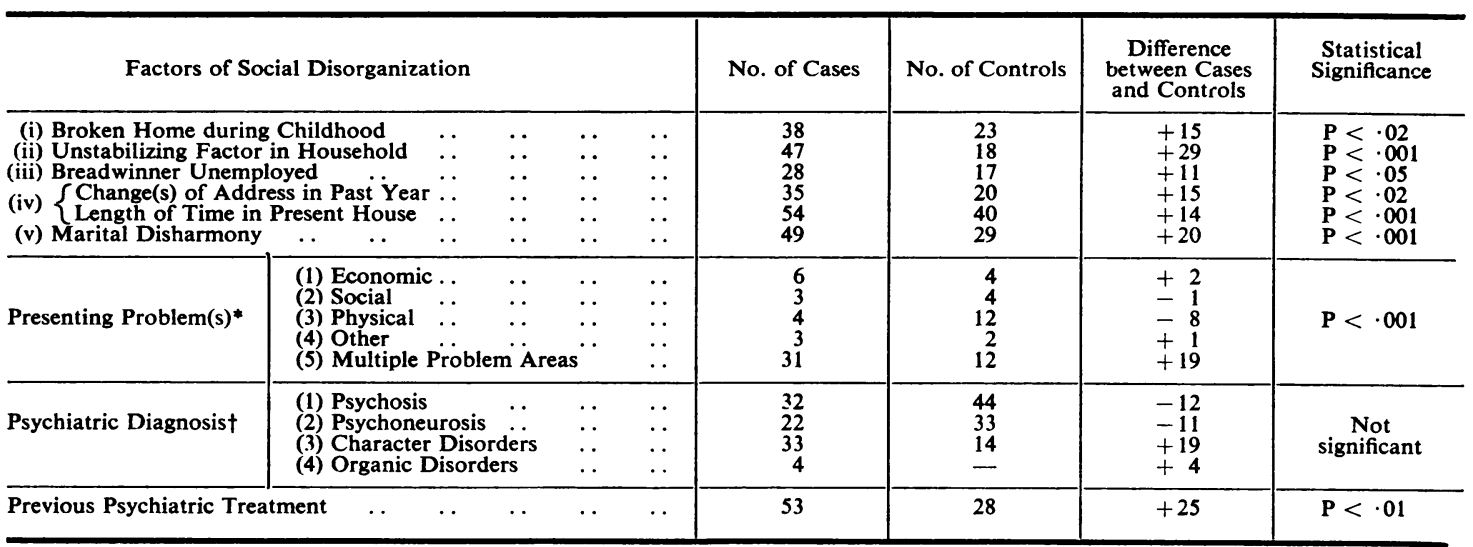

* $\chi^{2}$ computed for multiple problem areas $v$. other categories.

$\dagger \chi^{2}$ computed for character disorders and psychoneurosis $v$. psychosis and organic disorders.

47 ( 52 per cent.) of the attempted suicides had experienced such an unstabilizing event in their household in the year before admission compared with eighteen ( 20 per cent.) of the controls.

(iii) Unemployment.-The employment of the breadwinner of the patient's household in the year before admission was examined. Where the patient was married the husband was considered the breadwinner and in other cases, the patient was so regarded.

28 (34 per cent.) of such breadwinners were unemployed compared with seventeen ( 20 per cent.) of the controls. The degree of unemployment among the attempted suicides is most revealing when the unemployment figure of 34 per cent. is compared with 3.76 per cent. for Edinburgh residents as a whole (Ministry of Labour, Edinburgh).

It was found that 22 of the 28 attempted suicides who were unemployed were unmarried breadwinners compared with eight of the seventeen controls. Although frequency of changes of job was much the same, 32 of the attempted suicides' breadwinners changed jobs during the year before admission compared with 23 in the control group; more of the former being unmarried and more of the latter married.

(iv) Change(s) of Address.-35 (38 per cent.) of the attempted suicides had changed residence once or more in the year before admission compared with twenty ( 22 per cent.) of the controls. The majority of attempted suicides had moved to poorer housing areas and to situations of higher person/room density, but there was an opposite trend among the controls. In addition, thirty (33 per cent.) of the attempted suicides shared their dwelling compared with thirteen (14 per cent.) of the controls, the majority of the former being unmarried. More unmarried than married persons in both groups changed their address.

A corollary to change of address was the length of time the patient had lived at his present address. 54 ( 59 per cent.) of the attempted suicides had lived at their present address for less than 5 years compared with forty (44 per cent.) of the controls.

(v) Marital Disharmony.-Separation or divorce was, by definition, an indication of marital disharmony. Social workers' reports on all patients provided information regarding marital disharmony in other cases. All cases included in the category of marital disharmony demonstrated moderate to severe marital conflicts and/or periodic separations of marital partners occurring for a year or more previous to the attempt.

49 (89 per cent.) in the suicide group had experienced marital disharmony compared with only 29 (48 per cent.) of the controls. 
(3) Presenting Problem(s), Diagnosis, and Previous Psychiatric Treatment (Table III).

(i) Presenting Problem(s).-31 (25 per cent.) of the attempted suicides reported that they were experiencing problems in two or more areas compared with twelve (13 per cent.) of the controls. This finding, coupled with the high incidence of broken homes, unstabilizing events in the household, changes in address, and unemployment, suggests that the problems faced by the attempted suicides were more numerous and complex.

(ii) Diagnosis.-There was no significant difference at the $\cdot 05$ level between the distribution of diagnoses in attempted suicides and controls. However, there were over twice as many character disorders among the attempted suicides as among the controls (33 as opposed to 14), which suggests differences in the reactions of the attempted suicides and the controls to stress in their environment.

(iii) Previous Psychiatric Treatment.-53 (58 per cent.) of the attempted suicides had had previous psychiatric treatment, and 35 of them had made a previous suicide attempt. This is in contrast with 28 (31 per cent.) of the controls, who by definition had not previously attempted suicide, but had had previous psychiatric treatment.

\section{DisCUSSION}

Stengel and Cook (1958) found a lower proportion of single people among persons who committed suicide than among the survivors of suicide attempts. This they attributed partially to a higher average age among the suicides. The high incidence of attempted suicide among single persons, especially men, has often been attributed to social isolation. In this study it was found that the majority of single persons who attempted suicide were living in complex situations composed of a family member or members, relative(s), friend(s), and/or boarder(s). This type of living arrangement may well have contributed to these patients' numerous and complex social problems. We did not find the excessive proportion of widowed persons of either sex in the attempted suicide group compared with the Edinburgh population that Stengel reports.

Stengel compared his attempted suicide samples with the total hospital population from which the samples were drawn. This comparison leaves the unanswered question: "What are the similarities and differences in sex, age and marital status between the total hospital population and the population at risk from which it was drawn?" Stengel compared the age groups in two of his four groups of attempted suicides with the rest of the hospital population, but only for females.

In the present study of attempted suicides it was found that a considerable proportion ( 46 per cent.) had made previous attempts. This rate is higher than the rates of previous attempts in any of Stengel's four groups of attempted suicides which he reports as $22 \cdot 4,33 \cdot 3,37 \cdot 1$, and $27 \cdot 6$ per cent.

As far as is known the majority of admissions for attempted suicide in Edinburgh are made to Ward 3, whereas Stengel states that "the proportion of admissions after attempted suicide to mental observation wards in London is about 10 per cent."* The relative low and diverse rates of previous suicide attempts among his groups may be related to this selection process.

It was found that half of the attempted suicides had experienced the absence and/or death of a family member in the year before admission. In findings reported elsewhere it was pointed out that two-thirds of this group also came from broken homes (Bruhn, 1962). Thus, it seems that coming from a broken home is not in itself so significant as the repetitiono of a similar disorganizing event later in life.

The finding of a high unemployment rate amonge the breadwinners of individuals who attempted suicide was most striking compared to the low rate for the city of Edinburgh during the same time interval. This not only suggests that these families were experiencing some degree of poverty but also that unemployment gave rise to marital disharmony. This is partially corroborated by the finding that a third of the attempted suicides who had an unemployed breadwinner were separated or divorced.

A significantly higher proportion of the attempted suicides than of the controls had made one or more changes of residence in the year before admission. As Sainsbury (1955) points out, spatial mobility promotes social and cultural isolation. It can be considered that attempted suicides have not fostered close friendships, and seem to be people without roots.

Marital disharmony seems to be the most outstanding factor in this study as in that of Kessel and

* There are four situations in which attempted suicides are not

(1) when the attempted suicide is an ex-mental hospital patient and

when the attempted suicide is an ex-mental hospital patient and
is directly re-admitted to hospital,

(2) when the attempted suicide is treated by the general practitioner,

when the attempted suicide obtains surgical attention in other
hospitals and is not transferred to Ward 3,

4) when the attempt is 
Lee (1962). The role of marital disharmony or of the breaking home cannot be overstressed, especially in the light of the previous factors of social disorganization of which it may be a result. The complexity of the factors of social disorganization is emphasized by the findings regarding the problem areas which the attempted suicides related as being the precipitating factors of their attempt. 35 per cent. of the attempted suicides reported problems in two or more areas compared to 13 per cent. of the controls.

It may be that the greater number of character disorders among the attempted suicides reflects the patterned way in which these individuals have learned to cope with their environment, especially when confronted with complex social problems. The controls, who were largely psychotic or psychoneurotic and who did not experience the consistent high degree of social disorganization found among the attempted suicides, coped with their problems by attending an out-patient clinic.

Future research in the area of attempted suicide should continue to focus on this sociological problem by the study of the interdependence of social factors and the discovery of patterns that may lead to suicide attempts.

\section{SUMMARY}

This study examines five factors of social disorganization, the broken home, unstabilizing factor in the household, unemployment, change(s) of address, and marital disharmony, among a case group of 91 attempted suicides and a matched sample of 91 controls. The greater prevalence of disorganization in each of these areas in the case group compared with the controls is discussed.

I am grateful to Dr. J. K. Slater for permission to report these findings on Ward 3 patients and to the staffs of Ward 3 of the Royal Infirmary, Edinburgh, the Psychiatric Out-Patient Clinic of the Royal Infirmary, and the Jordanburn Nerve Hospital, for their helpful co-operation in making this project possible.

\section{REFERENCES}

Batchelor, I. R. C. (1955). Brit. med. J., 1, 595. and Napier, M. B. (1953). Brit. J. Delinq., 4, 99.

Bruhn, J. G. (1962). J. ment. Sci., 108, 772.

Dahlgren, K. G. (1945). "On Suicide and Attempted Suicide". Lindstedts Univ.-Bokhandel, Lund.

General Registry Office, Edinburgh (1952). Census 1951. City of Edinburgh, H.M.S.O., Edinburgh.

Harrington, J. A., and Cross, K. W. (1959). Brit. med. J., $2,463$.

Kessel, N., and Lee, E. McC. (1962). Scot. med. J., 7, 130.

Palmer, D. M. (1941). J. nerv. ment. Dis., 93, 421.

Piker, P. (1938). Amer. J. Psychiat., 95, 97.

Reitman, F. (1942). J. ment. Sci., 88, 580.

Sainsbury, P. (1955). "Suicide in London: An Ecological Study", Maudsley Monographs, No. 1. Chapman and Hall, London.

Stengel, E., and Cook, N. G. (1958). "Attempted Suicide: Its Social Significance and Effects", Maudsley Monographs No. 4. Chapman and Hall, London.

Woodside, M. (1958). Brit. med. J., $2,411$.

Zilboorg, G. (1936). Arch. Neurol. Psychiat. (Chicago), 35, 270. 